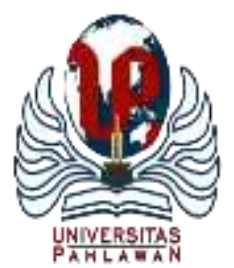

\title{
JURNALBASICEDU
}

Volume 5 Nomor 6 Tahun 2021 Halaman 6005 - 6010

Research \& Learningin Elementary Education

https://jbasic.org/index.php/basicedu

\section{Gaya Kepemimpinan Kepala Sekolah sebagai Sistem Kontrol dan Pengaruhnya terhadap Kinerja Operator Sekolah Dasar}

\author{
Zulfan $^{1 凶}{ }^{凶}$, Musifuddin ${ }^{2}$, Hary Murcahyanto ${ }^{3}$ \\ Universitas Hamsanwadi, Indonesia ${ }^{1,2,3}$ \\ E-mail: zulfanbelanting@gmail.com
}

\begin{abstract}
Abstrak
Penelitian ini bertujuan untuk mengetahui pengaruh kepemimpinan kepala sekolah sebagai sistem kontrol terhadap kinerja operator sekolah. Penelitian ini merupakan kuantitatif dimana penelitian kuantitiatif merupakan penelitian yang menggunakan astatistik sebagai alat analisisnya. Pengumpulan yang dilakukan dalam penelitian ini menggunakan kuesioner. Kuesioner yang terdiri dari 45 item pertanyaan digunakan untuk memperoleh data mengenai gaya kepemimpinan kepala sekolah. Sampel penelitian ini adalah 26 operator sekolah dasar yang ada di Kecamatan Sambelia. Analisis data menggunakan analisis regresi linier sederhana menggunakan SPSSm 20.0. Hasil penelitian ini menunjukkan bahwa nilai korelasi (R) sebesar 0,994 dan nilai koefisien korelasi (R Square) sebesar 0,988 yang memberikan makna bahwa besarnya pengaruh kepemimpinan kepala sekolah terhadap kinerja operator sekolah adalah 98\% dan sisanya adalah pengaruh dari faktor lain, selain itu besarnya nilai $\mathrm{F}$ hitung $=1987,954$ dengan tingkat signifikansi sebesar $0,000<0,05$, dengan demikian model regresi dapat digunakan untuk memprediksi variabel kinerja operator sekolah, dengan demikian dapat disimpulkan bahwa terdapat pengaruh yang positif dan signifikan antara variabel kepemimpinan kepala sekolah (X1) terhadap variabel kinerja operator sekolah (Y).
\end{abstract}

Kata Kunci: gaya kepemimpinan, sistem kontrol, kinerja operator

\begin{abstract}
This study aims to determine the effect of the principal's leadership as a control system on the performance of school operators. This research is quantitative where quantitative research is research that uses statistics as an analytical tool. The collection carried out in this study used a questionnaire. A questionnaire consisting of 45 question items was used to obtain data on the principal's leadership style. The sample of this study were 26 elementary school operators in Sambelia District. Data analysis used simple linear regression analysis using SPSSm 20.0. The results of this study indicate that the correlation value $(R)$ is 0.994 and the correlation coefficient ( $R$ Square) is 0.988 which means that the magnitude of the influence of the principal's leadership on the performance of school operators is $98 \%$ and the rest is the influence of other factors, besides the magnitude of the value of $F$ count $=1987.954$ with a significance level of $0.000<0.05$, thus the regression model can be used to predict the school operator's performance variable, thus it can be concluded that there is a positive and significant influence between the principal's leadership variable (X1) on the variable school operator performance $(Y)$.
\end{abstract}

Keywords: leadership style, control system, operator performance

Copyright (c) 2021 Zulfan, Musifuddin ,Hary Murcahyanto

$\triangle$ Corresponding author :

Email : zulfanbelanting@gmail.com

DOI : $\quad$ https://doi.org/10.31004/basicedu.v5i6.1693

ISSN 2580-3735 (Media Cetak)

ISSN 2580-1147 (Media Online) 
6006 Gaya Kepemimpinan Kepala Sekolah sebagai Sistem Kontrol dan Pengaruhnya terhadap Kinerja Operator Sekolah Dasar - Zulfan, Musifuddin ,Hary Murcahyanto

DOI: https://doi.org/10.31004/basicedu.v5i6.1693

\section{PENDAHULUAN}

Pendidikan memiliki peran penting dan menempati posisi sentral dalam pembangunan karena berorientasi pada peningkatan kualitas sumber daya manusia. Pendidikan merupakan proses transformasi nilai-nilai budaya sebagai kegiatan pewarisan budaya dari satu generasi ke generasi lainnya. Nilai-nilai budaya tersebut mengalami proses transformasi dari generasi sebelumnya ke generasi sekarang ke masa depan (Irmayani et al., 2018; Lian et al., 2018; Tobari et al., 2018). Sekolah sebagai bagian dari sistem pendidikan Nasional tentunya memerlukan perhatian dan pengelolaan yang serius. Oleh karena itu, kepemimpinan sekolah masa depan dengan perkembangan yang pesat dan perubahan masyarakat yang terbuka membutuhkan kemampuan yang lebih kreatif, inovatif dan dinamis. Tipe pemimpin yang diharapkan adalah seseorang yang dapat mempengaruhi orang lain dan memiliki kekuatan manajerial (Ozuruoke et al., 2011). Seluruh warga sekolah khususnya kepala sekolah selaku pimpinan yang bertanggung jawab terhadap kualitas sekolah yang dipimpinnya memiliki kesadaran bahwa sekolah sebagai sistem sosial merupakan organisasi yang dinamis dan tempat berlangsungnya proses pembudayaan dan pemberdayaan warga sekolah (Khasanah et al., 2019). Asumsi umumnya adalah bahwa ada atau tidak adanya pemimpin sekolah yang efektif, iklim sekolah yang positif, dan sikap positif guru, secara langsung atau tidak langsung, dapat mempengaruhi kinerja sekolah dan prestasi siswa (Dumay, 2009; Griffith, 2014; Hallinger, 2013; Hallinger \& Heck, 2010).

Pemimpin yang efektif adalah orang yang memiliki kemampuan untuk mengembangkan kapasitas sekolah untuk meningkatkan kinerja melalui pemberian memotivasi bagi guru, staf dan siswa. Administrasi sekolah yang membangun kapasitas sekolah melalui gaya kepemimpinan dan manajemen yang efektif dapat mempengaruhi kinerja warga sekolah. Pemimpin sekolah harus memiliki atau mampu mengembangkan kapasitas untuk bekerja dengan staf untuk fokus pada tujuan yang telah direncanakan (Theses \& Kay Hardman, 2011). Untuk berhasil dalam mencapai tujuan tersebut, kepala sekolah memiliki peran yang sangat penting dalam mengkoordinasikan, mengarahkan, dan menyelaraskan sumber daya pendidikan yang tersedia. Kepemimpinan kepala sekolah merupakan salah satu faktor yang dapat mendorong sekolah untuk dapat mewujudkan visi, misi, tujuan, dan sasaran melalui program sekolah yang dilaksanakan secara terencana dan bertahap.

Peraturan Menteri Pendidikan Nasional Nomor 13 Tahun 2007 tentang standar kepala sekolah adalah bahwa kepala sekolah harus memiliki: (a) kompetensi pribadi, (b) kompetensi manajerial, (c) kompetensi kewirausahaan, (d) kompetensi supervisi, dan (e) kompetensi sosial. Peran kepala sekolah sebagai pemimpin diharapkan dapat mewujudkan fungsi dan proses kepemimpinan dalam pendidikan sekolah secara keseluruhan. Keberhasilan pendidikan sekolah ditentukan oleh kemampuannya untuk mempengaruhi, menggerakkan, dan memotivasi individu (guru) untuk terlibat dalam tujuan pendidikan yang telah ditetapkan.

Gaya kepemimpinan merupakan sebuah norma perilaku yang ditampilkan oleh seseorang ketika ia mempengaruhi perilaku orang lain (Husaini, 2013). Bentuk kepemimpinan yang ditunjukkan oleh seorang kepala sekolah adalah teknik atau cara yang dilakukan kepala sekolah untuk mempengaruhi sumber daya manusia di sekolah agar berperilaku sesuai dengan apa yang diinginkan untuk mencapai tujuan sekolah. Sedangkan dimensi dan indikator variabel gaya kepemimpinan kepala sekolah yang dimaksud adalah, (1) hubungan (hubungan pimpinan dan bawahan); (2) memiliki kualitas; (3) hak anggota; dan (4) kewajiban dan tanggung jawab. Kepemimpinan yang efektif, yaitu tipe kepemimpinan yang berhasil membujuk, mendorong, mempengaruhi, dan memimpin pengikut dengan menggunakan berbagai metode dan strategi yang tepat untuk bersama-sama mencapai tujuan yang telah ditentukan (Yamin et al., 2016).

Gaya kepemimpinan kepala sekolah sebagai sebuah manajemen kontrol merupakan sistem informasi untuk berkomunikasi dan berinteraksi bagi pada manajemen sekolah sehingga dapat berbagi pengalaman untuk memecahkan masalah sehingga dapat memudahkan organisasi tersebut bertahan (Devie et al., 2019). Kepala sekolah sebagai sebuah sistem kontrol merupakan engendali yang dapat dijadikan sebagai motivasi 
6007 Gaya Kepemimpinan Kepala Sekolah sebagai Sistem Kontrol dan Pengaruhnya terhadap Kinerja Operator Sekolah Dasar - Zulfan, Musifuddin, Hary Murcahyanto

DOI: https://doi.org/10.31004/basicedu.v5i6.1693

kerja bagi semua yang ada pada lingkungan sekolah sehingga dapat mencapai tujuan bersama (Wee et al., 2014). Secara keseluruhan, kepala sekolah memberikan dukungan pada bidang akademik dan administrasi melalui serangkaian arahan dan instruksi kepada warga sekolah untuk melakukan tugas sebagaimana yang diberikan agar mencapai tujuan sebgaimana yang (Basit et al., 2017). Secara pragmatis, kepala sekolah sebagai seorang pemimpin pendidikan adalah seorang fasilitator dalam memecahkan masalah (Imhangbe et al., 2018; Okoji, 2016; Somech, 2005).

Masalah motivasi dan kinerja guru serta tenaga kependidikan telah menjadi bahan perdebatan dan perhatian dalam sistem dan standar pendidikan. Di sebagian besar negara berkembang di dunia termasuk Indonesia, telah tumbuh kesadaran tentang motivasi guru dan tenaga kependidikan yang merupakan kunci penjaminan mutu dalam sistem pendidikan. Diakui bahwa setiap negara yang tujuan untuk mempertahankan standar tinggi dan kualitas atau mencapai jaminan kualitas dalam sistem pendidikannya harus memperhatikan kebutuhan guru dan tenaga kependidikan dan memotivasi mereka dengan tingkat keseriusan yang tinggi. Oleh karena itu, tujuan dari penelitian ini adalah untuk membahas secara kritis pentingnya gaya kepemimpinan kepala sekolah dan motivasi kepala sekolah terhadap kinerja tenaga kependidikan yakni operator sekolah dasar di Kecamatan Sambelia.

Kepala sekolah sebagai pemimpin harus mampu memberikan pengaruh kepada orang lain. Seorang pemimpin memiliki sifat superior yang mampu membawa orang lain pada kondisi tertentu. Seorang kepala sekolah harus mampu mempengaruhi orang lain ke arah perubahan yang sesuai dengan tuntutan situasi (Andriani et al., 2018). Kepemimpinan adalah suatu cara untuk memberikan pengaruh sosial kepada orang lain, agar orang lain melakukan suatu proses seperti yang diinginkan oleh seorang pemimpin.

Kepala sekolah merupakan instrumen penting dalam pendidikan. Gaya kepemimpinan kepala sekolah juga merupakan cermin dari keberhasilan proses pendidikan di sekolah dimana ia memimpin. Gaya kepemimpinan kepala sekolah memainkan peran utama dalam meningkatkan kinerja guru dan tenaga kependidikan atau dalam sistem pendidikan tersebut. Kepala sekolah dapat mempengaruhi kinerja guru dan tenaga kependidikan terutama operator sekolah secara positif atau negatif karena mereka menentukan kualitas penyampaian instruksional dan juga mempengaruhi kualitas pendidikan dalam implementasi kebijakan pendidikan. Mereka harus dipertimbangkan ketika menangani isu-isu seperti: jaminan kualitas; kualitas penyampaian (pengajaran), kualitas konteks dan kualitas hasil belajar (Ibrahim, 2013).

\section{METODE PENELITIAN}

Penelitian ini bersifat kuantitatif. Menurut Musfiqon (2012) kuantitatif difokuskan pada fenomena objektif yang diteliti secara kuantitatif. Penelitian ini menggunakan metode korelasi parsial, korelasi parsial digunakan untuk analisis atau pengujian hipotesis apabila peneliti bermaksud untuk mengetahui pengaruh atau hubungan variabel bebas dengan variabel terikat, dimana salah satu variabel bebas dikendalikan (Sugiyono, 2012). Desain penelitian ini menggunakan ex post facto. Menurut Sugiyono (2012) desain penelitian ex post facto bertujuan untuk menyelidiki peristiwa yang telah terjadi kemudian mundur untuk mengetahui faktorfaktor penyebab terjadinya peristiwa tersebut.

Pengumpulan data dalam penelitian ini menggunakan kuesioner. Menurut Widoyoko (2012) kuisioner dilakukan dengan memberikan seperangkat pernyataan kepada responden untuk ditanggapi sesuai dengan permintaan pengguna. Skala data yang digunakan adalah skala Likert. Jika ada kesulitan dalam memahami kuesioner, responden dapat langsung bertanya kepada peneliti. Kuesioner yang terdiri dari 45 item pertanyaan digunakan untuk memperoleh data mengenai kompetensi manajerial kepala sekolah, kompetensi guru, prestasi belajar siswa, dimana setiap variabel penelitian terdiri dari 15 item pertanyaan. Sampel penelitian ini adalah 26 operator sekolah dasar yang ada di Kecamatan Sambelia. Pengumpulan data menggunakan model kuesioner Skala Likert. Analisis data menggunakan analisis regresi sederhana menggunakan SPSS. 
6008 Gaya Kepemimpinan Kepala Sekolah sebagai Sistem Kontrol dan Pengaruhnya terhadap Kinerja Operator Sekolah Dasar - Zulfan, Musifuddin,Hary Murcahyanto

DOI: https://doi.org/10.31004/basicedu.v5i6.1693

\section{HASIL DAN PEMBAHASAN}

Berdasarkan hipotesis dapat diketahui bahwa terdapat pengaruh yang signifikan kepemimpinan kepala sekolah terhadap prestasi belajar siswa. Kedua, ada pengaruh yang signifikan kinerja guru terhadap prestasi belajar siswa. Ketiga, ada pengaruh signifikan kepemimpinan kepala sekolah dan kinerja guru secara bersamasama terhadap prestasi belajar siswa. Di bawah ini kami menyajikan hasil analisis menggunakan model regresi sederhana dan berganda.

Tabel 1. Output Variabels Entered/Removed ${ }^{a}$

\begin{tabular}{cccc}
\hline Model & $\begin{array}{c}\text { Variabels } \\
\text { Entered }\end{array}$ & $\begin{array}{c}\text { Variabels } \\
\text { Removed }\end{array}$ & Method \\
\hline 1 & $\begin{array}{l}\text { Kepemimpinan } \\
\text { kepala sekolah }\end{array}$ & \\
\multicolumn{3}{c}{ a. } & Depender \\
b. & All requested variabel entered & \\
\hline
\end{tabular}

Tabel di atas menjelaskan tentang variabel yang dimasukkan serta metode yang digunakan. Dalam hal ini variabel yang imasukkan dalam analisis ini adalah kepemimpinan kepala sekolah sebagai variabel independen dan kinerja operator sekolah sebagai variabel dependen dan metode yang digunakan dalam analisis ini adalah metode enter.

Tabel 2. Output Model Summary

\begin{tabular}{|c|c|c|c|c|}
\hline Model & $\mathrm{R}$ & R Square & $\begin{array}{l}\text { Adjusted R } \\
\text { Square }\end{array}$ & $\begin{array}{l}\text { Std. Error of } \\
\text { the Estimate }\end{array}$ \\
\hline 1 &, $994^{\mathrm{a}}$ & ,998 & ,998 & 2,002 \\
\hline
\end{tabular}

Tabel di atas menjelaskan besarnya nilai korelasi (R). dengan demikian besarnya nilai korelasi (R) di dapatkan sebesar 0,994 dan besarnya nilai koefisien korelasi ( $\mathrm{R}$ Square) sebesar 0,988 yang memberikan makna bahwa besarnya pengaruh kepemimpinan kepala sekolah terhadap kinerja operator sekolah adalah $98 \%$ dan sisanya adalah pengaruh dari faktor lain.

Tabel 3. Output Coefficients ${ }^{a}$

\begin{tabular}{|c|c|c|c|c|c|}
\hline \multirow[b]{2}{*}{ Model } & \multicolumn{2}{|c|}{$\begin{array}{l}\text { Unstandarized } \\
\text { Coefficients }\end{array}$} & \multirow{2}{*}{$\begin{array}{c}\begin{array}{c}\text { Unstandariz } \\
\text { ed } \\
\text { Coefficients }\end{array} \\
\text { Beta }\end{array}$} & \multirow[b]{2}{*}{$\mathrm{t}$} & \multirow[b]{2}{*}{ Sig } \\
\hline & B & $\begin{array}{l}\text { Std. } \\
\text { Error }\end{array}$ & & & \\
\hline $1 \quad$ (Constant) & $-3,667$ & 3,392 & & $-1,081$ & 290 \\
\hline $\begin{array}{l}\text { Kepemimpinan } \\
\text { kepala sekolah }\end{array}$ & 1,024 & ,023 & 994 & 44,586 & ,000 \\
\hline
\end{tabular}

Berdasarkan tabel 3 diketahui nilai constant-nya adalah -3,667 dan nilai kepemimpinan kepala sekolah adalah 1,024. Dari keterangan tersebut kita dapat memperoleh persamaan regresi sebagai berikut:

$\mathrm{Y}=-3,667+1.024 \mathrm{X}$

Berdasarkan persamaan regresi di atas dapat disimpulkan bahwa ketika skor gaya kepemimpinan kepala sekolah sebesar 98 maka dapat diprediksi bahwa peningkatan kinerja operator sekolah tersebut adalah :

$$
\mathrm{Y}=-3,667+1.024 .98=-11,409+100,35=96,68
$$


6009 Gaya Kepemimpinan Kepala Sekolah sebagai Sistem Kontrol dan Pengaruhnya terhadap Kinerja Operator Sekolah Dasar - Zulfan, Musifuddin ,Hary Murcahyanto

DOI: https://doi.org/10.31004/basicedu.v5i6.1693

Dengan demikian dapat dikatakan bahwa nilai konstanta positif menunjukkan pengaruh positif variabel independen yakni gaya kepemimpinan kepala sekolah. Bila pengaruh gaya kepemimpinan kepala sekolah sebagai sistem kontrol nail sebesar satu satuan maka kinerja operator sekolah dasar naik sebesar satu satuan juga.

Tabel 4. ANOVA ${ }^{\mathrm{a}}$

\begin{tabular}{llrrrrr}
\hline Model & & Sum of & & & & \\
\multicolumn{1}{l}{ Squares } & \multicolumn{1}{c}{ df } & Mean Square & \multicolumn{1}{c}{ F } & \multicolumn{1}{c}{ Sig. } \\
\hline 1 & Regression & 7968,263 & 1 & 7968,263 & 1987,954 &, $000^{\mathrm{b}}$ \\
& Residual & 96,199 & 24 & 4,008 & & \\
& Total & 8064,462 & 25 & & & \\
\hline
\end{tabular}

a. Dependent Variable: Kinerja Operator Sekolah

b. Prediktor: (Constant). Kepemimpinan Kepala Sekolah

Dari output tersebut diketahui bahwa besarnya nilai $\mathrm{F}$ hitung $=1987,954$ dengan tingkat signifikansi sebesar $0,000<0,05$, dengan demikian model regresi dapat digunakan untuk memprediksi variabel kinerja operator sekolah dengan demikian dapat disimpulkan bahwa terdapat pengaruh yang positif dan signifikan antara variabel kepemimpinan kepala sekolah (X1) terhadap variabel kinerja operator sekolah (Y).

\section{KESIMPULAN}

Bentuk kepemimpinan yang ditunjukkan oleh kepala sekolah memberikan suasana dan iklim yang baik dimana warga sekolah saling mempercayai antara semua yang ada disekolah, dengan memperhatikan kenyamanan kerja operator sekolah, memberikan inspirasi untuk bekerja dengan mengutamakan hasil yang terbaik. Selain itu kepala sekolah juga memberikan pengakuan sehingga aktivitas kerja operator sekolah berjalan sebagaimana yang diharapkan. Dengan demikian hasil penelitian untuk hipotesis pertama menyimpulkan bahwa terdapat pengaruh gaya kepemimpinan kepala sekolah terhadap kinerja operator sekolah di Kecamatan Sambelia.

\section{UCAPAN TERIMA KASIH}

Terimakasih kepada dosen Pascasarjana Universitas Hamzanwadi yang telah memberikan suport sehingga penelitian ini dapat terselesaikan.

\section{DAFTAR PUSTAKA}

Andriani, S., Kesumawati, N., \& Kristiawan, M. (2018). The Influence Of The Transformational Leadership And Work Motivation On Teachers Performance. International Journal Of Scientific And Technology Research, 7(7), 19-29.

Basit, A., Sebastian, V., \& Hassan, Z. (2017). Impact Of Leadership Style On Employee Performance (A Case Study On A Private Organization In Malaysia). Int. J. Account. Bus. Manag, 5, 2289-4519.

Devie, D., Mangoting, Y., \& Soengkono, M. (2019). Pengaruh Leadership Style Terhadap Learning Organization. Ekuitas (Jurnal Ekonomi Dan Keuangan), 2(3), 427-446. Https://Doi.Org/10.24034/J25485024.Y2018.V2.I3.3962

Dumay, X. (2009). Origins And Consequences Achievement. Educational Administration Quarterly, 45(4), $523-555$.

Griffith, J. (2014). Relation Of Principal Transformational Leadership To School Staff Job Satisfaction, Staff Turnover, And School Performance. Journal Of Educational Administration, 42(3), 333-356. 
6010 Gaya Kepemimpinan Kepala Sekolah sebagai Sistem Kontrol dan Pengaruhnya terhadap Kinerja Operator Sekolah Dasar - Zulfan, Musifuddin, Hary Murcahyanto

DOI: https://doi.org/10.31004/basicedu.v5i6.1693

Https://Doi.Org/10.1108/09578230410534667

Hallinger, P. (2013). Leading Educational Change: Reflections On The Practice Of Instructional And Transformational Leadership. Cambridge Journal Of Education, 33(3), 329-351. Https://Doi.Org/10.1080/0305764032000122005

Hallinger, P., \& Heck, R. H. (2010). Hallinger(1998)Exploring The Principal's Contribution To School Effectiveness; 1980-1995.Pdf. 9(2), 157-191.

Husaini, U. (2013). Manajemen Teori,Praktik, Dan Riset Pendidikan. Jakarta : Pt Bumi Aksara.

Ibrahim, A. S. (2013). Principal Leadership Style, School Performance , And Principal Effectiveness In Dubai Schools. International Journal Of Research Studies In Education, 2(1), 41-54.

Imhangbe, O. S., Okecha, R. E., \& Obozuwa, J. (2018). Principals' Leadership Styles And Teachers' Job Performance: Evidence From Edo State, Nigeria. Educ. Manag. Adm. Leadersh, 47, 909-924.

Irmayani, H., Wardiah, D., \& Kristiawan., M. (2018). The Strategy Of Sd Pusri In Improving Educational Quality. International Journal Of Scientific And Technology Research, 7(7), 113-121.

Khasanah, U., Kristiawan, M., \& Tobari. (2019). The Implementation Of Principals' Academic Supervision In Improving Teachers' Professionalism In The State Primary Schools. International Journal Of Scientific \& Technology Research, 8(8).

Lian, B., Kristiawan, M., \& Fitriya, R. (2018). Giving Creativity Room To Students Through The Friendly School's Program. International Journal Of Scientific And Technology Research, 7(7), 1-7. Https://Doi.Org/10.31219/Osf.Io/Zebpd

Okoji, O. O. (2016). Relationship Between Secondary School Principals' Leadership Style And Teachers' Job Performance In Selected Rural Communities Of Ondo State, Nigeria. Ann. Modern Educ, 8, 27-36.

Ozuruoke, A. A., Rdu, P. ., \& Abdulkarim, M. (2011). Leadership Style And Business Educators' Job Performance In Senior Secondary Schools In A Changing Environment. J. Educ. Soc. Res., 1, 149-155.

Somech, A. (2005). Directive Versus Participative Leadership: Two Complementary Approaches To Managing School E Ectiveness. Educ. Adm. Q, 41, 777-800.

Theses, G., \& Kay Hardman, B. (2011). Scholar Commons Teacher' S Perception Of Their Principal' $S$ Leadership Style And The Effects On Student Achievement In Improving And Non-Improving Schools Scholar Commons Citation. January. Http://Scholarcommons.Usf.Edu/Etdhttp://Scholarcommons.Usf.Edu/Etd/3726

Tobari, Kristiawan, M., \& Asvio, N. (2018). The Strategy Of Headmaster On Upgrading Educational Quality In Asean Economic Community (Aec) Era. International Journal Of Scientific And Technology Research, 7(4), 72-79.

Wee, S. H., Foong, S. Y., \& Tse, M. S. C. (2014). No Titlemanagement Control System And Organisational Learning: The Effects Of Design And Use. Accounting Research Journal, 27(2), 169-187.

Yamin, M., Risnita, \& Warnida. (2016). The Relationship Between School Cultures And The Principal's Leadership Style And The Effectiveness Of The Principal's Leadership. International Journal Of Scientific Research And Management, January. Https://Doi.Org/10.18535//jsrm/V4i10.04 